Review Article

\title{
Evidence on the cost-effectiveness of lifelong antiretroviral therapy for prevention of mother-to-child transmission of HIV: Implications for resource-limited countries in sub-Saharan Africa
}

Peslie Gibson Ngambi ${ }^{a}$, Aubrey Chichonyi Kalungia ${ }^{b *}$, Francis Kalemeera ${ }^{c}$, IIse Truter ${ }^{d}$, Michael Law ${ }^{e}$, Brian Godman ${ }^{f, g}, h$, Derick Munkombwe ${ }^{b}$

${ }^{a}$ Division of Population Health, Health Services Research and Primary Care, University of Manchester, Manchester, United Kingdom

${ }^{b}$ Department of Pharmacy, University of Zambia, Lusaka, Zambia

${ }^{c}$ Department of Pharmacology, Pharmacy Policy and Practice, University of Namibia, Windhoek, Namibia

${ }^{d}$ Drug Utilization Research Unit (DURU), Department of Pharmacy, Nelson Mandela

Metropolitan University, Port Elizabeth, South Africa

${ }^{e}$ University of British Columbia, Vancouver, Canada

Division of Clinical Pharmacology, Karolinska Institute, Stockholm, Sweden. Email:

Brian.Godman@ki.se

${ }^{g}$ Strathclyde Institute of Pharmacy and Biomedical Sciences, University of Strathclyde, Glasgow, UK. Email: Brian.Godman@strath.ac.uk

${ }^{h}$ Health Economics Centre, Liverpool University Management School, Liverpool, UK.

Email: Brian.Godman@liverpool.ac.uk

*Corresponding author: Aubrey C. Kalungia, Email: chichokalungia@gmail.com or

ckalungia@unza.zm

(Accepted for publication Expert Review of Pharmacoeconomcis and Outcomes Research - Please keep CONFIDENTIAL)

\begin{abstract}
Introduction: The 2016 World Health Organization (WHO) consolidated guideline recommends lifelong antiretroviral therapy (ART) for all HIV-infected pregnant and breastfeeding women for preventing mother-to-child HIV transmission (PMTCT). Ambiguity remains about the cost-effectiveness of this strategy in resource-limited developing countries. Areas Covered: We reviewed model-based studies on the cost-effectiveness of lifelong ART (formerly Option $\mathrm{B}+$ ) relative to previous WHO guidelines for PMTCT. Our search using PubMed, Medline and Google Scholar for articles on Option B + resulted in the final inclusion of seven studies published between 2012 and 2016. The Consolidated Health Economic Evaluation Reporting Standards (CHEERS) checklist was used to assess the quality of reporting. Outcomes of interest, which included infant infections averted, maternal quality and length of life, and the Incremental Cost Effectiveness Ratio (ICER), were used in comparing cost-effectiveness.

Expert Commentary: Despite most model-based studies favouring lifelong ART (Option $\mathrm{B}+$ ) in terms of cost-effectiveness in comparison to Options A and B, inclusiveness of the evidence remains weak for generalization largely because setting specificity for providing lifelong ART to all pregnant and breastfeeding women may differ significantly in each setting. Therefore, future cost-effectiveness studies should be robust, setting-specific, and endeavor to assess the willingness and ability to pay of each setting.
\end{abstract}


KEY WORDS: Cost-effectiveness, Antiretroviral therapy, Option B+, HIV, Modeling, Mother-to-child transmission, Implications, Resource-limited countries

\section{INTRODUCTION}

Every year, an estimated 1.4 million women living with HIV become pregnant [1]. The majority of these women are based in sub-Saharan Africa where approximately 4,500 new HIV infections among young women occurred every week [2]. Realizing that achieving an HIVfree era means eliminating transmission, the global community embarked on an ambitious plan to attain zero new HIV infections among infants born from infected women by 2020 [3]. In 2015 , it was reported that about $83 \%$ of the estimated 150,000 children newly infected with HIV were in eastern and southern Africa where coverage of antiretroviral therapy (ART) among HIV-infected pregnant women was about 79\% (range 70-88\%) [4]. Despite significant gains recently made in reducing the number of children dying from HIV/AIDS-related illness by $62 \%$ [5] and the increase in treatment coverage in sub-Saharan Africa, where an estimated 13.8 million people were receiving ART at the end of 2016 [6] compared with only 50,000 a decade earlier [7], transmission from mother-to-child remains quite widespread.

Prevention of mother-to-child transmission (PMTCT) programs have been implemented worldwide primarily aimed at eliminating transmission of HIV to children born from HIVinfected mothers. Over the years, PMTCT guidelines from the World Health Organization (WHO) have evolved over several iterations [7, 8] (Table 1). The most recent 2016 WHO guideline recommends initiating upon diagnosis, life-long ART with tenofovir, lamivudine (or emtricitabine) and efavirenz among all HIV-positive pregnant and breastfeeding women regardless of CD4 count or clinical staging [9]. This presents a shift from the previous WHO recommendations which provided optional strategies [7].

Table 1: Evolution of WHO PMTCT recommendations. Key: AZT = Zidovudine, sdNVP = single dose Nevirapine, NVP $=$ Nevirapine, $3 \mathrm{TC}=$ Lamivudine

\begin{tabular}{|c|c|c|c|c|}
\hline \multirow{2}{*}{$\begin{array}{l}\text { PMTCT } \\
\text { Guideline }\end{array}$} & \multicolumn{2}{|c|}{ Recommendation for preventing HIV transmission } & \multirow{2}{*}{$\begin{array}{l}\text { Treatment } \\
\text { Initiation } \\
\text { Threshold }\end{array}$} & \multirow{2}{*}{$\begin{array}{l}\text { Year } \\
\text { Strategy } \\
\text { Launched }\end{array}$} \\
\hline & Mother: & Infant: & & \\
\hline $\begin{array}{l}\text { Option A } \\
{[10]}\end{array}$ & $\begin{array}{l}\text { If breastfeeding: Daily AZT } \\
\text { commenced at } 14 \text { weeks gestation } \\
\text { (Antepartum) then sdNVP + } \\
\text { AZT/3TC at onset of labor } \\
\text { (Intrapartum) then AZT/3TC } \\
\text { continued for } 7 \text { days (Postpartum) } \\
\text { OR } \\
\text { If not breastfeeding: AZT with } \\
\text { sdNVP before and during delivery } \\
\text { with either AZT, or NVP for } 6 \\
\text { weeks postpartum }\end{array}$ & $\begin{array}{l}\text { If breastfeeding: NVP daily } \\
\text { from birth upto } 7 \text { days after } \\
\text { cessation of breastfeeding. }\end{array}$ & $\begin{array}{l}\text { CD4 }<350 \\
\text { cells } / \mu \mathrm{L}\end{array}$ & 2006 \\
\hline $\begin{array}{l}\text { Option B } \\
{[10]}\end{array}$ & $\begin{array}{l}\text { If breastfeeding: Triple ARVs from } \\
14^{\text {th }} \text { week of pregnancy up to one } \\
\text { week after cessation of } \\
\text { breastfeeding; } \\
\text { OR } \\
\text { If not breastfeeding: Triple ARV } \\
\text { drug therapy administered from } 14^{\text {th }} \\
\text { week of pregnancy until delivery. }\end{array}$ & $\begin{array}{l}\text { Irrespective of feeding } \\
\text { method: NVP or AZT daily } \\
\text { from birth upto } 4-6 \text { weeks }\end{array}$ & $\begin{array}{l}\text { CD4 }<500 \\
\text { cells } / \mu \mathrm{L}\end{array}$ & 2010 \\
\hline
\end{tabular}




\begin{tabular}{|l|l|l|l|l|}
\hline $\begin{array}{l}\text { Option B+ } \\
{[10]}\end{array}$ & $\begin{array}{l}\text { ART for all pregnant and } \\
\text { breastfeeding women regardless of } \\
\text { CD4 count or WHO clinical staging }\end{array}$ & $\begin{array}{l}\text { Irrespective of feeding } \\
\text { method: NVP or AZT daily } \\
\text { from birth upto 4 - 6 weeks }\end{array}$ & $\begin{array}{l}\text { As soon as } \\
\text { diagnosed }\end{array}$ & 2013 \\
\hline $\begin{array}{l}\text { 'Test \& } \\
\text { Treat All' } \\
{[9]}\end{array}$ & $\begin{array}{l}\text { Lifelong ART for all pregnant and } \\
\text { breastfeeding women regardless of } \\
\text { CD4 count or WHO clinical staging }\end{array}$ & $\begin{array}{l}\text { Irrespective of feeding } \\
\text { method: AZT and NVP daily } \\
\text { from birth upto 6 weeks }\end{array}$ & $\begin{array}{l}\text { As soon as } \\
\text { diagnosed }\end{array}$ & 2016 \\
\hline
\end{tabular}

Notwithstanding the current WHO recommendation of life-long ART (previously referred to as Option $\mathrm{B}+$ ), the prior PMTCT guidelines remain in use in a number of settings yet to make the transition [11]. However, each of these particular PMTCT guidelines tends to give isolated and conflicting evidence in favor of any given strategy, showing each of them to be efficacious. For instance, available evidence suggests Option A and B regimens for PMTCT had similar efficacy in clinical trial settings $[12,13,14,15]$. Aside this evidence, there has been insufficient head-to-head comparison on cost-effectiveness of the respective strategies in resource-limited settings. This is a concern for key decision makers in most low- and middleincome countries (LMICs) in sub-Saharan Africa that are making the transition to 'test \& treat all'.

Resource scarcity is an important consideration in LMICs, with up to $70 \%$ of healthcare expenditures spent on medicines, much of which is out-of-pocket [16, 17]. Healthcare policy makers in LMICs are concerned with establishing not only that a change in treatment protocol is justified through being more clinically effective, but also concerned about the extra costs incurred. Across countries, healthcare payers aim to maximize health outcomes within their constrained resources [18], which includes striving to provide, or continuing to provide, universal healthcare $[17,19,20,21]$. Consequently, in order to have an efficient strategy that ensures value for money, a number of health-economic evaluations of available strategies have been conducted and published. These analyses have mainly been based on decision analytic modeling - a systematic approach to decision-making under conditions of uncertainty through the use of mathematical relationships to define a series of consequences resulting from all possible alternatives [22].

Deviation from the methods of health-economic evaluation and decision analytic modeling can influence the validity and generalizability of any findings, with the methods and assumptions having profound effects on the findings and consequently on payers' decisions [22]. In the studies reviewed in this paper, several assumptions were made in their models. For instance on fertility, Gopalappa et al [23] assumed that between ages 15 - 49, each woman in Kenya, Zambia, South Africa and Vietnam gave birth to between 2 to 6 children, respectively. In Zimbabwe, among several assumptions made, Ciaranello et al [24] assumed there was 100\% adherence to their PMTCT regimens among all women identified as HIV-positive on their first antenatal visit. A similar assumption was taken by Ishikawa et al [25] in Zambia. Therefore, it is important that assumptions and results be consistent across jurisdictions. Whereas a recent review of model-based cost-effectiveness analyses in developing countries by Karnon and Orji [18] suggested that Option $\mathrm{B}+$ was likely to be cost-effective relative to other PMTCT strategies (as adjudged from one comprehensive analysis across five model-based studies reported), their findings are yet to be corroborated. Importantly, their review highlighted that some evaluations omitted potentially important additional benefits. Consequently, they concluded that additional model analyses are required. This review aimed to provide additional perspectives pertaining to the health-economic evaluation of lifelong ART (Option $\mathrm{B}+$ ) strategy relative to other WHO recommendations in order to give guidance to decision-makers in sub-Sahara African countries and other LMICs seeking to improve the management of HIV patients within limited resources. 


\section{METHODS}

\subsection{Literature search}

We conducted a literature search using PubMed, Medline and Google Scholar databases to identify original publications. As lifelong ART (Option B+) for PMTCT was a relatively new strategy, the search period was not limited but included all available articles published on the subject search criteria so far prior to this review. An initial search for titles and abstracts published in English was conducted in April 2017 using the search terms: 'Option B+ OR PMTCT (Cost-effectiveness OR Cost-Utility OR Cost benefit OR Economic OR Cost) AND Prevention of Mother to Child Transmission OR HIV'. Furthermore, reference lists of the identified studies and reviews were searched manually.

\subsection{Study selection}

Using methods of identification, screening, eligibility and inclusion of published records described by Moher et al. [26], full text retrieval was subsequently undertaken and subjected to the inclusion and exclusion criteria. Non-model-based evaluation studies were excluded. Out of the possible publications initially identified in the literature search $(n=1038)$, a total of seven studies that met the selected search criteria were included. Details of the review process are shown in figure 1.

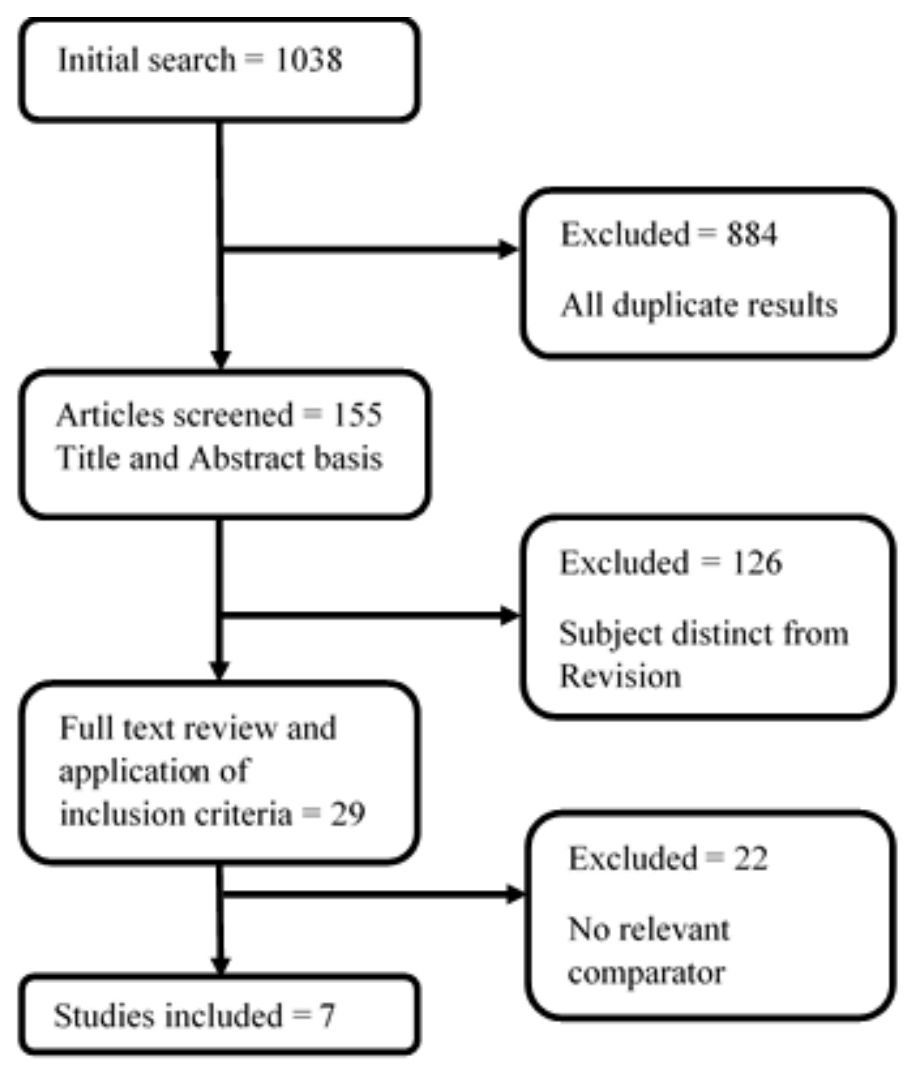

Figure I: Literature selection flow chart

\subsection{Data Extraction and Quality Assessment}

The publication related characteristics of each study were extracted (Table 2). The characteristics included: Author, publisher/journal, country, perspective, outcome measure, time horizon, model type and funders. The outcome of cost-effectiveness, such as the Incremental Cost Effectiveness Ratio (ICER) was extracted as reported without making any adjustments for the year, exchange rate or purchasing power parity employed. The Consolidated Health Economic Evaluation Reporting Standards (CHEERS) [27] was used to assess the quality of reporting of the published papers. 


\section{RESULTS}

\subsection{Quality Assessment}

Based on the 24-item CHEERS checklist criteria (Available online URL: http://www.equator-network.org/wp-content/uploads/2013/04/Revised-CHEERS-ChecklistOct13.pdf [9]), most studies had good reporting quality with respect to sensitivity analyses, perspectives, time horizons, methods, and limitations in main body of the publication.

\subsection{Overview of included studies}

The publication year for the seven included studies ranged from 2012 to 2016. Most of these studies were country-specific model-based economic evaluations. Only one study [23] investigated more than one country. A healthcare system (payer) perspective was taken in all the studies, although this was not explicitly stated in some. Infant infections averted was the most common outcome measure amongst all the studies. Whilst two studies $[25,28]$ applied a fixed time horizon of 10 years, the other studies applied a lifetime horizon [24, 29, 30]. Most of the studies were funded by medical research agencies such as the National Institute for Health (NIH) and non-profit organizations such as Bill \& Melinda Gates Foundation and Elizabeth Glaser Pediatric AIDS Foundation (EGPAF), respectively. None of the studies were funded by the pharmaceutical industry. Only one study [31] had the lead author affiliated to a pharmaceutical company. The study characteristic overview is summarized in Table 2.

The primary population of interest in most studies was HIV-positive pregnant women and their infants. However, some of the studies modeled the life and HIV risk of all women of child-bearing age [30]. Quality-adjusted life years (QALYs) were a complementary outcome measure in two studies $[23,30]$. The QALY being a generic measure of health aims to reflect the impact of interventions on individuals' length of life and health-related quality of life in a single measure [32]. Only three studies used the Disability-Adjusted Life Year (DALY) - a measure of disease burden [30]. Although the DALY is relatively common in economic evaluations, it differs from QALY in many aspects. Historically, QALYs have been used more often for pricing, reimbursement, and funding decisions [20, 33, 34].

\subsection{Review of Specific Studies}

Ciaranello et al [24] evaluated the clinical impact, cost and cost-effectiveness of the different WHO-recommended PMTCT guidelines in Zimbabwe. These guidelines, as stated before, started as early as 2013 advocating for the initiation of lifelong ART among all HIVpositive pregnant women, regardless of CD4+ cell count. In this study, three validated and linked computer models were used to simulate a cohort of HIV positive pregnant women. One of the linked models was the Mother-to-Child HIV transmission model, which modeled a single pregnancy and delivery. The other two were both Cost Effectiveness of Preventing AIDS Complications (CEPAC) models, which included: the CEPAC infant model - a model of HIV infection and mortality among breastfed infants; and the CEPAC adult model in which HIV progression among postpartum women was modeled [24]. The study population mean age was 24 years, mean CD4 count was 451 cells $/ \mathrm{mm}^{3}$ and assumed pregnant women to present for their first antenatal care visit at 24-28 weeks of pregnancy. A subsequent breastfeeding period of 18 months was considered. The simulated interventions were: no treatment, single-dose nevirapine (sdNVP); WHO Option A; Option B; and Option B+, respectively. The outcomes considered by Ciaranello et al were infant and maternal Life Expectancy (LE) and lifetime healthcare costs using the 2008 US dollar (US\$) costing and prices. Although the reported costs excluded non-drug related costs of providing ART, the impact of implementation costs in the antenatal period was examined. 
Overall, the study by Ciaranello et al found that among infants born to HIV-infected women, Options $\mathrm{B}$ and $\mathrm{B}+$ had similarly lower pediatric HIV infection rates $(5.7 \%)$ as compared to Option A (7.5\%), sdNVP (14.2\%) and no antenatal treatment $(24.8 \%)$, respectively [24]. The projected undiscounted Life Expectancy (LE) (including HIV infected and non-infected infants) ranged from 38.35 years (with no antenatal ARVs) to 44.18 years (with Option $\mathrm{B}$ and $\mathrm{B}+$ ) respectively. Over longer time horizons, the undiscounted lifetime costs per infant ranged from US\$ 730 (with no antenatal ARVs) to US\$ 350 (with Options B and $\mathrm{B}+$ ). The authors argued that PMTCT regimens that prevented more infant infections also led to lower lifetime healthcare costs [24]. In terms of projected maternal LE from delivery, there was a paradox in that 'no treatment' had a better outcome (21.25 years) than sdNVP (20.94 years). They attributed this to impact of resistance to non-nucleotide reverse transcriptase inhibitors on follow-up of first-line ART. The other interventions; Options A, B and $\mathrm{B}+$ had $21.26,21.30$ and 22.42 years respectively. Clearly, the differences in projected maternal LE were quite insignificant across the interventions, except for Option B+ which recorded a gain in LE greater than 1.0 years compared to options A and B. In the long run, maternal costs were found to be similar for 'no antenatal ARVs', sdNVP and Option A. In terms of costs, Option B and B+ had undiscounted costs of US\$ 8450 and US\$ 9820, respectively. Their findings favored Option $\mathrm{B}+$ as the more cost-effective option followed by Option B. However, the authors postulated that Option B had deleterious effects following the interruption of treatment. Additionally, univariate and multivariate sensitivity analyses were conducted to show how robust the findings were to the assumption. The parameters subjected to sensitivity analyses included access to antenatal and postnatal care with a focus on key PMTCT, pediatric, maternal and cost parameters [24]. In their study, even with an assumed reduced access to PMTCT services or access to CD4 testing, Option B remained less costly and more effective than no treatment, sdNVP, and Option A. The ICER of Option B + compared to Option B also remained similar at US\$ 1370 per Life Year Saved (LYS). However, under the reported rates of Lost to Follow-Up (LTFU) from maternal postnatal HIV care, the ICER reduced to US\$ 850 per LYS. Under clinical parameters, when the risk of virological failure was altered to 1.5 times higher than the base case, Option B did not dominate Option A; but when increased two-fold, Option A dominated Option B. Nonetheless, policy conclusions remained the same.

Fasawe et al [28] conducted a cost-effectiveness study of the standard of care for PMTCT (i.e. current practice in 2010 versus WHO recommended Options A, B and B+ for PMTCT) in Malawi. A decision tree and Markov model was used in this study. The authors analyzed an annual cohort of 66,500 pregnant women diagnosed with HIV on their first antenatal visit and simulated a 10-year time horizon. In the Markov model, women transitioned between four states based on the CD4 count and death as the absorbing state. Outcomes measured by Fasawe et al were similar to Ciaranello et al except for an inclusion of DALYs. Cost per infant HIV infection averted, maternal life year gained and DALYs were assessed. According to Fasawe et al, Option A was found to avert less infections and cost less than options $\mathrm{B}$ and $\mathrm{B}+$, respectively [28]. The reported ICER for Option A, B and B+ was US\$ 844, US\$ 1,331 and US\$ 1,265 per infection averted respectively. Furthermore, the ICER for options A, B and B+ were US\$ 37, US\$ 60 and US\$ 57 per DALY averted, respectively. Nevertheless, using the ICER comparing to the current practice as the base case, Option A turned out to be costeffective with an ICER of US\$ 38, whereas Options B and B+ had US\$ 68 and US\$ 64 per infection averted, respectively. Regarding ten-year maternal survival rates which they reported improved more than four-fold with Option B+, Fasawe et al reported an ICER per life year gained of US\$ 341, US\$ 338 and US\$ 455 for Options A, B and B+ respectively, all relative to the current practice. Everything else being equal, including universal CD4 testing availability, Option A remained cost-effective according to their study. From the one-way 
sensitivity analyses they performed, arguably Option A had lower ICER versus current practice with alteration to the cost, efficacy of ARVs and transmission rates only that it had a lower ICER versus current practice. Accordingly, for Options B and B+ to attain a lower ICER compared to Option A, the cost of ART had to reduce by up to $40 \%$ and only if the coverage of CD4 count testing was lower than $73 \%$ in Malawi [28]. However, if Options B and B+ led to a larger increase in DALYs, this may merely imply both strategies have a higher ICER than Option A and not necessarily that either is 'less cost-effective'.

Tweya et al [29] evaluated the cost-effectiveness of Option B+ (lifelong ART) relative to Option B in Malawi. Their study used an individual-based simulation model to simulate 10000 women and their infants. First and second pregnancy outcomes were modeled. Following the first pregnancy, the infant infection rate was similar for both Options B and $\mathrm{B}+$ at $15 \%$. At the start of the second pregnancy, more women were on lifelong ART (Option B+) at 39\% as compared to only $18 \%$ on Option B. However, the rate of infant infection only differed by $1 \%$ (11.3\% for Option $\mathrm{B}+$ and $12.3 \%$ for Option B). The ICER of lifelong ART (Option $\mathrm{B}+$ ) compared with Option B per DALY averted range was US\$ 500 to US\$ 1300. The study concluded that lifelong ART (Option B+) was cost-effective compared to Option B as it was associated with a lower ICER with regards to averting infections during the second pregnancy, having taken into account the total future costs and lost lifetime of the infected infants.

Similarly, VanDeusen et al [30] evaluated the cost-effectiveness of lifelong ART (Option $\mathrm{B}+$ ) compared to Option B in multiple pregnancies in Ghanaian women. They used a statetransition model to compare lifetime costs and health benefits associated with the two strategies for PMTCT. The outcomes measured were infant HIV infections averted, life expectancy and QALYs. When discounted lifetime costs were compared, Option B cost US\$ 6,254 and lifelong ART (Option B+) cost US\$ 12,624, respectively. Despite Option B+ being more costly compared to Option B, it yielded a substantial gain in QALYs over Option B. The reported ICER for Option B+ was US\$ 785 per QALY gained or US\$ 618 per life-year gained, assuming maternal and infant quality-of-life weights were ignored. Their cost-effectiveness analysis showed that even when the annual cost of HIV care increased 1.5-fold in Ghana, the ICER remained below the country's gross domestic product (GDP) per capita. VanDeusen et al also concluded in favor of lifelong ART (Option $\mathrm{B}+$ ) being cost-effective as compared to Option B in resource-limited countries.

A deterministic model was used by Gopalappa et al [23] to determine the costs and benefits of lifelong ART (Option B+) versus Options A and B for PMTCT. Four countries included in the evaluation were Kenya, South Africa, Vietnam and Zambia. The model used simulated births, breastfeeding, and HIV infection in women. The outcomes were infant infections averted and partner sexual transmissions averted by ART. Gopalappa et al found lifelong ART (Option $\mathrm{B}+$ ) to be cost-effective compared to Options $\mathrm{A}$ and $\mathrm{B}$, respectively. For instance, considering total cost per total mother-to-child and sexual transmissions averted, Option $\mathrm{B}+$ was found to be cost-saving compared to 'no PMTCT', Options A and B in all four countries. They also considered the cost of PMTCT per child infection averted for Option A versus Option $\mathrm{B}+$ after having eliminated the strongly dominated 'No PMTCT' and Option B arm from subsequent cost-effectiveness analysis. Provided that ART eligibility was CD4+ cell count less than 350 cells $/ \mu 1$, lifelong ART (Option B + ) incurred an additional cost of approximately US\$ 6,000, US\$ 6,800, US\$23, 000, and US\$21, 500 per infant infection averted in Kenya, Zambia, South Africa, and Vietnam, respectively, compared with Option A.. However, if ART eligibility was expanded to a CD4+ cell count less than 500 cells $/ \mu 1$, lifelong ART (Option B+) would incur an additional cost of approximately US\$ 6,300, US\$ 7,200, US\$13,500 and US\$ 9,800 per infant infection averted in the four countries, respectively, compared with Option A 
[23]. The authors highlighted the limitations of this simple deterministic model in the discussion.

Ishikawa et al [25] used a decision analytic model to conduct an economic evaluation of the 2010 and 2013 WHO recommendations for PMTCT in Zambia. The comparators in this study were options A, B and B+. The outcomes of interest were infant and partner infections averted, as well as changes in QALYs. An ICER per infection averted and QALY were also calculated. The study reported a 33\% reduction in infant infections in favor of 2013 WHO guidelines (Options B and $\mathrm{B}+$ ). In terms of partner infections averted for serodiscordant couples over a 10 year time horizon, the risk of HIV transmission reduced by $72 \%$ following a shift from Option A to Option B, and further reduced by 15\% when shifting from Option B to Option B+. All these findings were based on an annual cohort of 600000 pregnant women with an HIV rate of $16.1 \%$ [25]. The ICER was found to be US\$ 1,034 , US $\$ 1,140$ and US\$1,406 per infant infection averted for Options A, B and B+, respectively. Taking into consideration the partner infections averted, the ICER reduced to US\$1,023 and US\$1,254 for Option B and lifelong ART (Option B+), respectively. The ICER per QALY gained due to infant infections averted was reported to be US\$ 88 and US\$ 155 for Option B and lifelong ART (Option B+), respectively. Taking into consideration the partner infections averted, the ICER per QALY was found to be US\$ 77 and US\$ 132 for Option B and lifelong ART (Option B+) respectively. In terms of cost-effectiveness over a 10-year time horizon, , Options B and B+ appeared to have been dominant. A sensitivity analysis was conducted on the access and utilization of health services, discordance rate, and HIV prevalence, in order to examine the robustness of the findings. Option B and lifelong ART (Option $\mathrm{B}+$ ) remained cost-effective at altered access and utilization of health services. Under an altered discordance rate, Option B remained the dominant strategy compared to Option $\mathrm{A}$. In addition, at discordance rates of $40 \%$ and $5 \%$, lifelong ART (Option B+) was dominant and cost-effective respectively.

Kuznik et al [31] evaluated the cost-effectiveness of 18-months ART and life-long ART relative to that of other alternative strategies (sdNVP, dual ARV therapy or no treatment) for PMTCT in Uganda. A two-phased decision-based analytic model, which focused on multiple pregnancies and infant outcomes, was developed. This study only considered one clinical outcome of mother-to-child transmission and estimated the associated DALYs based on HIVattributable life expectancy as well as disability weights for HIV infection and AIDS. The study focused on ART eligible women based on their CD4 count. Costs considered for ART included drug acquisition costs and other healthcare utilization services such as physician and laboratory visits. However, for sdNVP and dual ARV therapy, only drug acquisition costs were considered. The cost per DALY for lifetime ART when compared to sdNVP, dual ARV therapy, and no therapy were US\$205, US\$ 354 and US\$ 172, respectively. In the same vein, 18-months ART (Option B) averted fewer DALYs but at a lower cost. The DALYs averted in Option B were 5.21, 3.22, and 8.58 when compared to sdNVP, dual therapy and no treatment, whereas the cost per DALY was US\$ 46, US\$ 99 and US\$34, respectively. 


\begin{tabular}{|c|c|c|c|c|c|c|}
\hline Author & $\begin{array}{l}\text { Publisher/ } \\
\text { Journal }\end{array}$ & Country & Perspective & Outcome measures & $\begin{array}{l}\text { Time } \\
\text { Horizon }\end{array}$ & Key Results \\
\hline $\begin{array}{l}\text { Ciaranello et al. } \\
(2013)[24]\end{array}$ & $\begin{array}{l}\text { Clinical } \\
\text { Infectious } \\
\text { Diseases }\end{array}$ & Zimbabwe & $\begin{array}{l}\text { Healthcare } \\
\text { (Payer) }\end{array}$ & $\begin{array}{l}\text { Infant infections averted, } \\
\text { maternal and infant LE, } \\
\text { healthcare costs }\end{array}$ & Lifetime & $\begin{array}{l}\text { Option B+ improved maternal and infant health } \\
\text { benefits (LE, } 39.04 \text { years; lifetime cost, } \\
\text { US } \$ 6620 \text { per mother-infant pair), with an ICER } \\
\text { of US } \$ 1370 \text { per YLS compared with Option B. }\end{array}$ \\
\hline $\begin{array}{l}\text { Fasawe et al. } \\
(2013)[28]\end{array}$ & PLoS ONE & Malawi & $\begin{array}{l}\text { Healthcare } \\
\text { system (Payer) }\end{array}$ & $\begin{array}{l}\text { Averted infant infection, DALYs, } \\
\text { maternal life years gained }\end{array}$ & 10 years & $\begin{array}{l}\text { Option B+ not only prevented infant infections, } \\
\text { but improved maternal survival more than four- } \\
\text { fold saving more than } 250,000 \text { maternal life } \\
\text { years, as compared to Option A or B. Option } \\
\mathrm{B}+\text { yielded favourable ICER of US } \$ 455 \text { per } \\
\text { life year gained over the current practice. }\end{array}$ \\
\hline $\begin{array}{l}\text { Gopalappa et al. } \\
\text { (2014) [23] }\end{array}$ & $\begin{array}{l}\text { AIDS. Wolters } \\
\text { Kluwer Health }\end{array}$ & $\begin{array}{l}\text { Kenya, South } \\
\text { Africa, } \\
\text { Vietnam, } \\
\text { Zambia }\end{array}$ & $\begin{array}{l}\text { Healthcare } \\
\text { system }\end{array}$ & $\begin{array}{l}\text { Child infections averted, PMTCT } \\
\text { costs }\end{array}$ & Lifetime & $\begin{array}{l}\text { Option B+ averted more child infections } \\
\text { compared with Option B in all four countries. } \\
\text { Option } \mathrm{B}+\text { was the most cost-effective strategy } \\
\text { costing between US } \$ 6000 \text { and US } \$ 23000 \text { per } \\
\text { infection averted compared with Option A. }\end{array}$ \\
\hline $\begin{array}{l}\text { Ishikawa et al. } \\
(2013)[25]\end{array}$ & PLoS One & Zambia & $\begin{array}{l}\text { Healthcare } \\
\text { system }\end{array}$ & $\begin{array}{l}\text { QALY, Infant and Serodiscordant } \\
\text { Partner and infections averted }\end{array}$ & 10 years & $\begin{array}{l}\text { Shift from Option A to Option B+ resulted in } \\
33 \% \text { HIV risk reduction among exposed infants, } \\
87 \% \text { among serodiscordant partners. }\end{array}$ \\
\hline $\begin{array}{l}\text { Tweya et al. } \\
(2016)[29]\end{array}$ & $\begin{array}{l}\text { AIDS. Wolters } \\
\text { Kluwer Health }\end{array}$ & Malawi & $\begin{array}{l}\text { Healthcare } \\
\text { system }\end{array}$ & $\begin{array}{l}\text { DALY, Infant infection averted, } \\
\text { healthcare costs (antenatal, } \\
\text { postnatal \& lifetime) }\end{array}$ & Lifetime & $\begin{array}{l}\text { Comparing Option } \mathrm{B}+\text { and Option } \mathrm{B} \text {, ICER } \\
\text { ranged between US } \$ 500 \text { and US } \$ 1300 \text { per } \\
\text { DALY averted. }\end{array}$ \\
\hline $\begin{array}{l}\text { VanDeusen et al } \\
\text { (2015) [30] }\end{array}$ & BioMed Central & Ghana & $\begin{array}{l}\text { Healthcare } \\
\text { system }\end{array}$ & $\begin{array}{l}\text { QALY, Infant infection averted, } \\
\text { ICER }\end{array}$ & Lifetime & $\begin{array}{l}\text { Option B+ theoretically prevented up to } 668 \\
\text { infant infections annually. Despite higher initial } \\
\text { ART costs, Option B+ cost US\$785/QALY } \\
\text { gained. }\end{array}$ \\
\hline $\begin{array}{l}\text { Kuznik et al. } \\
(2012)[31]\end{array}$ & Bull. WHO & Uganda & $\begin{array}{l}\text { Healthcare } \\
\text { system }\end{array}$ & DALY, Infant infections averted & Lifetime & $\begin{array}{l}\text { Compared to other PMTCT options, lifetime } \\
\text { ART (Option B+) averted } \\
19.20,11.87 \text { and } 31.60 \text { DALYs at a cost of US\$ } \\
205 \text {, US\$ } 354 \text { and US\$ } 172 \text { per DALY averted. }\end{array}$ \\
\hline
\end{tabular}

Table 2: Reviewed studies, notable outcomes measures and key results 


\subsection{Key Drivers of Cost-effectiveness}

Based on our review, the key drivers of cost-effectiveness identified in the studies included: fertility rate, birth interval, comparative ART eligibility (based on CD4+ count), infant infections averted, partner infections averted, fertility and live birth intervals. Others included: ART regimen effectiveness, life expectancies, access to antenatal (and postnatal) care, disease transmission probabilities, and increased future healthcare benefits versus costs for infected infants. As highlighted by VanDeusen et al [30], as the likelihood of accessing antenatal care positively increases to over $90 \%$ in the developing countries, lifelong ART (Option $\mathrm{B}+$ ) becomes more cost-effective because infants will be more likely to avoid HIV infection. Moreover, the incremental cost of Option B+ compared to other previous WHO recommendations for PMTCT decreased with an increase in the fertility rate and a decrease in the birth interval. [23].

\subsection{DISCUSSION}

\subsection{Implications for Policy}

Our overall findings suggest that life-long ART (Option B+) as a strategy for eliminating mother-to-child transmission of HIV provides good value for money. This strategy may be practically useful for developing countries in sub-Sahara Africa that tend to have high repeat pregnancy rates, limited access to CD4 testing, and have a long duration of breastfeeding by HIV-infected mothers. In line with the current 'test \& treat all' recommendation by WHO [9], the requirement that all HIV-positive women be put on life-long ART technically implies there will be no need for 'options' for PMTCT in practice. It therefore makes health-economic sense for policy-makers to prioritize pregnant women's health care needs in resource-limited settings. The success of this strategy will largely depend on ability of decision-makers in resource limited countries to afford the cost of maintaining all HIV-infected women on lifelong ART.

While each of the reviewed studies acknowledged the increased PMTCT cost associated with lifelong ART (Option $\mathrm{B}+$ ), none reported on the health budget impact - an increasingly important requirement among payers in LMICs when considering new treatment options [35]. As argued by Marseille et al [36], even if an intervention is categorized as cost-effective based on its cost per DALY averted, that intervention may still not represent the best use of a country's health budget. Realizing that resources are limited, we believe it is imperative for future studies to report on the budget impact of different treatment options, and possibly show the Cost-Effectiveness Acceptability Curve (CEAC).

Apart from its impact on reducing morbidity and mortality, including HIV transmission, evidence from this review further highlights that lifelong ART (Option $\mathrm{B}+$ ) potentially attains greater gains on QALY and life-expectancy for both the mother and infant, including serodiscordant partners. Importantly, despite the initial increased cost for most resource-limited countries, early initiation of life-long ART is modelled as cost-saving in the long term as the initial cost is partly offset by subsequent reduced costs associated with improved patients' quality of life. This includes decreased hospitalization and increased productivity for those women in gainful economic sectors, and prevention of HIV transmission to subsequent children. The key policy directions for healthcare systems in resource-limited countries is to ensure uninterrupted ART services, availability of ARVs, adherence and retention in care [9]. Clearly, lifelong ART as a strategy for PMTCT may have little benefit in resource-limited countries if HIV-infected women do not adhere to their treatment regimen or are not retained in HIV care programs (loss to follow-up) [37, 38, 39]. Given the current situation where 
different resources-limited African countries have different health system capacities, including different HIV epidemiology patterns, program quality and levels of ART coverage; additional interventions including human, infrastructure and fiscal resources may be required to maintain patients on ART in these settings. Recent evidence also suggests socio-cultural and technological (e.g. mobile phone-based) interventions may also come to the fore when making considerations to improve retention of postpartum women on ART care in Africa [40].

\subsection{Implications for Research}

In as much as each of the studies reported on the cost-effective intervention, they did not report on the Willingness to Pay (WTP) threshold per DALY averted for each of the healthcare systems. This is especially important in settings where there are high co-payments for medicines as well as issues of affordability [41]. Although many resource-limited countries have explicitly referred to the WHO criteria [42] to set WTP thresholds for an intervention that is considered cost-effective if its ICER is less than three- times the annual national GDP per capita, and very cost-effective if the ICER is less than one GDP per capita, there is growing evidence that use of these criteria has major limitations [36].

Although the reviewed studies considered the benefit of lifelong ART (Option B+) in terms of cost, life-years gained and averting infections to not only infants but also to serodiscordant partners among other outcomes, none of the studies looked at new infant infections averted, quality of maternal health outcomes and partner infections averted together, in addition to the ICER. Arguably, evaluating these three types of outcomes together would have potentially estimated the impact and cost-effectiveness of lifelong ART (Option B+) as a holistic outcome on the future health of mothers, infants and their partners.

The simple deterministic model used by Gopalappa et al and Ciaranello et al often falls short of establishing at which point a woman enters the model and subsequent state transitions within the projected time horizon. Factors that may account for direct treatment disutility (DTD), for instance ARV toxicity resulting in discontinuation of ART in the initial phases, tend to be omitted in such a model. Interestingly, Heath et al. [43] found that 58\% of ARV toxicity accounted for discontinuation of first line cART regimen within 2 years of initiation. Since the models did not consider DTD, they may over or under-estimate the utility of the interventions as they assumed no patient inconvenience resulting from taking the treatment [44]. Thomson et al. [45] put across a notion that the total focus on subsequent health-related outcomes for an intervention results in missing some key attributes that patients may value. It is therefore important to take into consideration the process utility when considering attributes of a given intervention in order to ensure a precise result of cost-effectiveness. Moreover, since routine and continuous laboratory monitoring of patients' CD4 count, viral load and other relevant clinical parameters would be required while on lifelong ART, this additional cost was not comprehensively modeled in majority of the studies reviewed. This needs to be addressed in future studies to aid decision making especially in resource-limited countries.

One limitation encountered with majority of the reviewed model-based studies is that cost analysis measures that aid healthcare decision-making were not robust. For instance, researchers would have done well to also conduct analysis of the Expected Value or Perfect Partial Information (EVPPI), which is a decision-theoretic measure of the cost of parametric uncertainty in decision-making used principally in health economic decision-making [43]. Another equally informative analytic measure of cost-effectiveness often used as alternative to ICER is the Incremental Net Monetary Benefit (INMB) that informs the willingness to Pay (WTP). Ideally, the INMB helps in resolving well-known problems associated with ICER 
when bootstrap replicates cover all four quadrants of the cost-effectiveness plane. Accordingly, researchers would confidently inform that the cost to derive the benefit from the intervention (lifelong ART) is less than the maximum amount that the decision-maker would be willing to pay for the benefit [46]. Understandably, the uptake and utilization of these complex measurements in cost-effectiveness analysis research was low.

\subsection{CONCLUSION}

The majority of the reviewed model-based studies favor lifelong ART (Option B+) to be a cost-effective intervention for PMTCT in resource-limited settings. However, the evidence remains weak for generalization to all other settings. This is largely because setting specificity for providing lifelong ART to all pregnant women and breastfeeding mothers may differ significantly in each setting with regards to HIV epidemiology, fertility rates, coverage of HIV testing and treatment services, including health system practice of maternal and child healthcare. It is therefore practical that the roll out of lifelong ART strategy for eliminating mother-to-child HIV transmission, particularly in resource-limited settings, should be gradual and ensure that it conforms to the local resource availability required to meet total annual costs of investment into implementing the strategy, including treatment monitoring requirements in each setting. Our study further reveals that when making a decision on the adoption of lifelong ART strategy, health economic evaluations should be robustly undertaken. This means not only including sensitivity and cost analysis measures that aid healthcare decision-making in combination with the full domains of health system assessment in each setting, but also utilize more inclusive cost-effectiveness models that evaluate effects of lifelong ART compared to alternative strategies for HIV prevention among pregnant and breastfeeding women, their infants and partners.

\subsection{EXPERT COMMENTARY}

It is our contention that future cost-effectiveness studies and setting-specific economic evaluations should endeavor to assess the willingness and ability to pay of each setting, and include some form of budget impact analysis for each setting. Researchers should also endeavor to include an analysis of the Expected Value of Perfect Partial Information (EVPPI). This goes for all health-economic evaluations that end with recommendations for further research. EVPPI could also be used to decide on the inclusion of Direct Treatment Disutility (DTD). It would be interesting to investigate how the use of EVPPI and INMB would inform cost-effectiveness analyses of lifelong ART strategy for PMTCT in resource-limited countries.

\subsection{FIVE-YEAR VIEW}

In low- and middle-income countries, the pressure on limited resources in healthcare will continue to grow as new health technologies which are typically more expensive than current standards continue to be launched. This in turn calls for increased utilization of healtheconomic evaluation tools to assist in ensuring efficiency as countries strive for universal access to quality and cost-effective healthcare. Consequently in the coming five years, healtheconomic evaluations will continue to be more relevant in resource-limited settings. However, the limited availability of health economists to lead the process in some of the developing countries, coupled by increased practice of payers' decision-making that is based largely on cost-minimization analysis rather than cost-effectiveness analysis, may potentially frustrate efforts to fully complement clinical decisions with health economics. However, this can be partly addressed using capacity building strategies including establishing health technology assessment units within each health system. 
In each setting, health programs and strategies require to be evaluated prior to implementation irrespective of sound clinical evidence. Consequently, if the assumptions are not robust enough, strategies such as lifelong ART may even potentially turn out to be economically catastrophic in some settings. At the rate we are moving in the global quest to attain zero HIV transmission there will be increased adoption of this strategy with the backing of the WHO. On the positive side, with recent evidence showing a life expectancy of ARTtreated HIV infected individuals being at par with non-infected individuals, it reinforces the evidence backing the current 'test and treat all' strategies recommended by WHO. In turn, this will accelerate implementation of lifelong ART as the strategy of choice for eliminating mother-to-child transmission of HIV in resource-limited countries.

\subsection{KEY ISSUES}

- Mother-to-child transmission of HIV, though virtually eliminated in developed countries, still remains a major challenge in low- and middle-income developing countries of sub-Saharan Africa which bear the huge brunt of the HIV/AIDS epidemic.

- In order to achieve total elimination and prevention of mother-to-child transmission of HIV, universal access to treatment (ARVs) for every pregnant and breastfeeding woman has to be achieved in all LMICs.

- Although PMTCT guidelines have evolved over the years from single dose nevirapine (sdNVP), dual ARV Therapy (Option A), short term HAART (Option B) to lifelong combination ART (Option B+) for HIV-infected pregnant woman, economic evaluation of these strategies must be a continuous process to ensure value for money evidence is generated when allocating the limited fiscal resources in resource-limited countries.

- So far, based on the ICER, a number of model-based studies have found lifelong ART (Option $\mathrm{B}+$ ) to be a cost-effective strategy for PMTCT especially in subsequent pregnancies.

- The pressure on limited resources in the healthcare sector will continue to grow as health technologies continue. This in turn calls for increased utilization of robust and comprehensive health economic evaluation tools to assist in ensuring efficiency in resource use in LMICs.

\section{Declaration of interest}

The authors declare no conflicts of interest associated with this work.

\section{REFERENCES}

1. WHO. WHO validates elimination of mother-to-child transmission of HIV and syphilis in Cuba: World Health Organization; 2017 [cited 2017 19th April]. Available from: http://www.who.int/mediacentre/news/releases/2015/mtct-hiv-cuba/en/

2. UNAIDS. Prevention Gap Report. United Nations; 2016.

3. WHO. Global health sector strategy on HIV 2016-2021. Towards ending AIDS: World Health Organization; 2016.

4. WHO. Global Health Observatory (GHO) data: Prevention of mother-to-child transmission (PMTCT): World Health Organization; 2017 [cited 2017 07-23]. Available from: http://www.who.int/gho/hiv/epidemic response/PMTCT text/en/

5. UNAIDS. Ending AIDS progress towards the 90-90-90 targets: Global AIDS Update 2017: Joint United Nations Programme on HIV/AIDS (UNAIDS); 2017 [cited 2017 07-26]. 
http://www.unaids.org/sites/default/files/media_asset/Global_AIDS update_2017 en. pdf

* Provides recent update on the status of global targets to eliminate HIV transmission

6. WHO. HIV/AIDS: Data and statistics: World Health Organization; 2017 [cited 2017 07-25]. Available from: http://www.who.int/hiv/data/en/

7. WHO. Guideline on when to start antiretroviral therapy and on pre-exposure prophylaxis for HIV. Geneva, Switzerland: World Health Organization; 2015.

8. WHO. New guidance on prevention of mother-to-child transmission of HIV and infant feeding in the context of HIV: World Health Organization; 2010 [cited 2017 06/06]. Available from: http://www.who.int/hiv/pub/mtct/PMTCTfactsheet/en/

9. WHO. Consolidated guidelines on the use of antiretroviral drugs for treating and preventing HIV infection: recommendations for a public health approach. World Health Organization; 2016.

10. WHO. Consolidated guidelines on the use of antiretroviral drugs for treating and preventing HIV infection: recommendations for a public health approach June 2013. World Health Organization; 2013.

11. UNAIDS. Global Plan towards the elimination of new HIV infections among children by 2015 and keeping their mothers alive 2011-2015. Geneva: UNAIDS; 2011.

12. Shapiro RL, Hughes M, Ogwu A, et al. Antiretroviral regimens in pregnancy and breast-feeding in Botswana. New England Journal of Medicine. 2010;362(24):22822294.

13. Taha TE, Li Q, Hoover DR, et al. Postexposure prophylaxis of breastfeeding HIVexposed infants with antiretroviral drugs to age 14 weeks: updated efficacy results of the PEPI-Malawi trial. JAIDS Journal of Acquired Immune Deficiency Syndromes. 2011;57(4):319-325.

14. Fowler MG, Coovadia H, Herron CM, et al. Efficacy and safety of an extended nevirapine regimen in infants of breastfeeding mothers with HIV-1 infection for prevention of HIV-1 transmission (HPTN 046): 18-month results of a randomized, double-blind, placebo-controlled trial. Journal of acquired immune deficiency syndromes (1999). 2014;65(3):366.

15. Jamieson DJ, Chasela CS, Hudgens MG, et al. Maternal and infant antiretroviral regimens to prevent postnatal HIV-1 transmission: 48-week follow-up of the BAN randomised controlled trial. The Lancet. 2012;379(9835):2449-2458.

16. Cameron A, Ewen M, Ross-Degnan D, et al. Medicine prices, availability, and affordability in 36 developing and middle-income countries: a secondary analysis. The Lancet.373(9659):240-249. doi: 10.1016/s0140-6736(08)61762-6.

17. Fadare JO, Adeoti AO, Desalu OO, et al. The prescribing of generic medicines in Nigeria: knowledge, perceptions and attitudes of physicians. Expert Review of Pharmacoeconomics \& Outcomes Research. 2016 2016/09/02;16(5):639-650. doi: 10.1586/14737167.2016.1120673.

18. Karnon J, Orji N. Option B+ for the prevention of mother-to-child transmission of HIV infection in developing countries: a review of published cost-effectiveness analyses. Health Policy and Planning. 2016;31(8):1133-1141.

**Conducted initial review of cost-effectiveness analyses and provided basis for further analyses and study of evidence on lifelong ART (Option B+) strategy for PMTCT

19. Malmstrom R, Godman B, Diogene E, et al. Dabigatran-a case history demonstrating the need for comprehensive approaches to optimize the use of new drugs. Frontiers in pharmacology. 2013;4:39. 
20. Godman B, Malmström RE, Diogene E, et al. Are new models needed to optimize the utilization of new medicines to sustain healthcare systems? Expert review of clinical pharmacology. 2015;8(1):77-94.

*Explians need and importance of optimising utilization of medicines in health care systems

21. Godman B, Shrank W, Andersen M, et al. Comparing policies to enhance prescribing efficiency in Europe through increasing generic utilization: changes seen and global implications. Expert Review of Pharmacoeconomics \& Outcomes Research. 2010 2010/12/01;10(6):707-722. doi: 10.1586/erp.10.72.

22. Briggs $\mathrm{AH}$, Claxton $\mathrm{K}$, Sculpher MJ. Decision modelling for health economic evaluation. Oxford University Press, USA; 2006.

23. Gopalappa C, Stover J, Shaffer N, et al. The costs and benefits of Option B+ for the prevention of mother-to-child transmission of HIV. AIDS. 2014;28:S5-S14.

** Modeled cost and benetifs of lifelong ART (Option B+) for PMTCT in four LMIC countries: Kenya, Zambia, South Africa, and Vietnam

24. Ciaranello AL, Perez F, Engelsmann B, et al. Cost-effectiveness of World Health Organization 2010 guidelines for prevention of mother-to-child HIV transmission in Zimbabwe. Clinical Infectious Diseases. 2013;56(3):430-446.

** Shows how replacing no treatment or sdNVP with Options A, B or B+ will improve maternal and infant outcomes and save money

25. Ishikawa N, Shimbo T, Miyano S, et al. Health outcomes and cost impact of the new WHO 2013 guidelines on prevention of mother-to-child transmission of HIV in Zambia. PLoS ONE. 2014;9(3):e90991.

**Shows potential risk reduction attained using each prevention strategy

26. Moher D, Liberati A, Tetzlaff J, et al. Preferred reporting items for systematic reviews and meta-analyses: the PRISMA statement. PLoS med. 2009;6(7):e1000097.

27. Husereau D, Drummond M, Petrou S, et al. Consolidated health economic evaluation reporting standards (CHEERS) - explanation and elaboration: a report of the ISPOR health economic evaluation publication guidelines good reporting practices task force. Value in Health. 2013;16(2):231-250.

*Illustrates, explains and elaborates the CHEERS criteria

28. Fasawe O, Avila C, Shaffer N, et al. Cost-effectiveness analysis of option B+ for HIV prevention and treatment of mothers and children in Malawi. PLoS ONE. 2013;8(3):e57778.

**Demonstates model of cost-effectiveness of lifelong ART (Option B+) in a LMIC

29. Tweya H, Keiser O, Haas AD, et al. Comparative cost-effectiveness of option $\mathrm{B}+$ for prevention of mother-to-child transmission of HIV in Malawi. AIDS. 2016;30(6):953962.

*Illustrates a model showing how lifelong ART (Option $\mathrm{B}+$ ) prevents more vertical transmissions of HIV than Option B

30. VanDeusen A, Paintsil E, Agyarko-Poku T, et al. Cost effectiveness of option B plus for prevention of mother-to-child transmission of HIV in resource-limited countries: evidence from Kumasi, Ghana. BMC infectious diseases. 2015;15(1):130.

**Demonstrates increase in maternal and pediatric QALY, including cost-effectiveness of lifelong ART (Option B+) strategy in a LMIC

31. Kuznik A, Lamorde M, Hermans S, et al. Evaluating the cost-effectiveness of combination antiretroviral therapy for the prevention of mother-to-child transmission of HIV in Uganda. Bulletin of the World Health Organization. 2012;90(8):595-603.

**Illustrates use of a two-phased mathematical model of evaluating cost-effectiveness of interventions 
32. Sassi F. Calculating QALYs, comparing QALY and DALY calculations. Health Policy and Planning. 2006;21(5):402-408. doi: 10.1093/heapol/czl018.

33. Paris V, Belloni A. Value in pharmaceutical pricing 2013. Available from: http://www.oecd-ilibrary.org/social-issues-migration-health/value-in-pharmaceuticalpricing 5k43jc9v6knx-en

34. Godman B, Gustafsson LL. A new reimbursement system for innovative pharmaceuticals combining value-based and free market pricing. Applied health economics and health policy. 2013;11(1):79-82.

35. Faleiros DR, Álvares J, Almeida AM, et al. Budget impact analysis of medicines: updated systematic review and implications. Expert Review of Pharmacoeconomics \& Outcomes Research. $2016 \quad 2016 / 03 / 03 ; 16(2): 257-266 . \quad$ doi: 10.1586/14737167.2016.1159958.

36. Marseille E, Larson B, Kazi DS, et al. Thresholds for the cost-effectiveness of interventions: alternative approaches. Bulletin of the World Health Organization. 2015;93(2):118-124.

37. Tweya H, Gugsa S, Hosseinipour M, et al. Understanding factors, outcomes and reasons for loss to follow-up among women in Option B+ PMTCT programme in Lilongwe, Malawi. Tropical Medicine \& International Health. 2014;19(11):1360-1366.

38. Tenthani L, Haas AD, Tweya $\mathrm{H}$, et al. Retention in care under universal antiretroviral therapy for HIV infected pregnant and breastfeeding women ("Option B+") in Malawi. AIDS (London, England). 2014;28(4):589.

39. Mirkuzie AH, Hinderaker SG, Sisay MM, et al. Current status of medication adherence and infant follow up in the prevention of mother to child HIV transmission programme in Addis Ababa: a cohort study. Journal of the International AIDS Society. 2011;14(1):50.

40. Geldsetzer P, Yapa HMN, Vaikath M, et al. A systematic review of interventions to improve postpartum retention of women in PMTCT and ART care. Journal of the International AIDS Society. 2016;19(1).

41. Godói IP, Santos AS, Reis EA, et al. Consumer Willingness to Pay for Dengue Vaccine (CYD-TDV, Dengvaxia $\left.{ }^{\circledR}\right)$ in Brazil; Implications for Future Pricing Considerations. Frontiers in pharmacology. 2017;8.

42. Sachs J. Commission on Macroeconomics and Health (2001) Macroeconomics and Health: Investing in Health for Economic Development. Geneva: World Health Organization.

43. Heath A, Manolopoulou I, Baio G. Estimating the expected value of partial perfect information in health economic evaluations using integrated nested Laplace approximation. Statistics in medicine. 2016;35(23):4264-4280.

44. Walmsley S, editor Update on Antiretroviral Treatment Failure and the Management of Treatment-Experienced HIV Infected Patients. Optimizing Therapy for Patients With Multidrug-Resistant HIV Review and Updates to the 2005 ICAAC Satellite Symposium, Management of Treatment-Experienced Patients. A Free CME/CE/CEU Monograph; 2006.

45. Thompson A, Guthrie B, Payne K. Do Pills Have No Ills? Capturing the Impact of Direct Treatment Disutility. PharmacoEconomics. 2016;34(4):333-336.

46. Net Monetary Benefit [online] York: York Health Economics Consortium; 2016 [cited 2017 06-17]. Available from: http://www.yhec.co.uk/glossary/net-monetary-benefit/ 